\title{
Correction to: Utilization of ceramic waste powder in cement mortar exposed to elevated temperature
}

\author{
Nahla Hilal $^{1}$ [ $\cdot$ Rawaa Dheyaa Saleh $^{1} \cdot$ Najwa B. Yakoob ${ }^{1} \cdot$ Qais Sahib Banyhussan $^{2}$
}

Published online: 17 July 2021

C) Springer Nature Switzerland AG 2021

\section{Correction to: \\ Innovative Infrastructure Solutions (2021) 6:35 \\ https://doi.org/10.1007/s41062-020-00403-x}

In the original publication of the article, the second point of the conclusion on page no. 11 is erroneously published as: $2140 \mathrm{~kg} \mathrm{~m}^{3}$ and $2100 \mathrm{~kg} / \mathrm{m}^{3}$ with the XML taggings.

The correct one should as: $2140 \mathrm{~kg} / \mathrm{m}^{3}$ and $2100 \mathrm{~kg} / \mathrm{m}^{3}$.

This has been corrected in this paper.

Nahla Hilal

nahla.naji@uofallujah.edu.iq

Rawaa Dheyaa Saleh

Rawaa.saleh@uofallujah.edu.iq

Najwa B. Yakoob

najwaalani67@gmail.com

Qais Sahib Banyhussan

qaisalmusawi@uomustansiriyah.edu.iq

1 Department of Scholarships and Foreign Relation,

University of Fallujah, Fallujah, Iraq

2 Highways and Transportation Engineering Department, Mustansiriayah University, Baghdad, Iraq 